\title{
A note on the effect of pre-slaughter transport duration on nutrient composition and fatty acid profile of broiler breast meat*
}

\author{
E. Zanetti ${ }^{1,3}$, S. Yalçın², C. Guler ${ }^{2}$ and M. Cassandro ${ }^{1}$ \\ ${ }^{1}$ University of Padova, Animal Science Department \\ Viale dell'Università 16, 37020 Legnaro, Padova, Italy \\ ${ }^{2}$ Ege University, Animal Science Department \\ TR-35100 Izmir, Turkey
}

(Received 8 March 2011; revised version 15 July 2011; accepted 9 August 2011)

\begin{abstract}
The aim of this study was to investigate the influence of pre-slaughter transport duration, as a stress factor, on nutrient and fatty acid composition of broiler breast meat. The study was conducted on 48 breast muscles obtained from Ross broilers slaughtered at the average weight of 1.8 or $2.6 \mathrm{~kg}, 36$ and 46 days old, respectively. Transport duration was 1.5 or $3 \mathrm{~h}$. Heavier broilers transported for longer duration had the higher protein content, while lighter broilers gave similar results. Lower moisture but higher lipid content was observed for the long transported broilers. Fatty acid composition was significantly influenced by body weight and transport duration: a lower content of PUFA was obtained for heavier broilers. Ratios of PUFA/SFA was lower in heavier broilers. A decrease in MUFA and a lower n-3/n-6 ratio was evidenced in the meat from broilers transported for longer duration.
\end{abstract}

KEY WORDS: broiler, transport, breast meat, nutrient, fatty acids

\section{INTRODUCTION}

Nutrient and fatty acid composition in meat has received considerable attention in recent years in view of its human health promoting properties and meat quality

\footnotetext{
* Supported by Abalığlu Yem, Soya ve Tekstil Sanayi A.Ş

${ }^{3}$ Corresponding author: e-mail: enrico.zanetti@unipd.it
} 
characteristics (Wood et al., 2004). The ratio between polyunsaturated (PUFA) and saturated (SFA) fatty acids and the ratio between n- 6 and n-3 fatty acids are considered two important indexes for nutritional evaluation of fat (Department of Health, 1994) due to their role in protecting the human body against cardiovascular related diseases. Several factors, including gender, age (DeSemet et al., 2004), diet (Szymczyk et al., 2001) and genotype (Zanetti et al., 2010) affects nutrient and fatty acid composition of meat.

Stress experience by the animals was investigated as one of the factors affecting the quality the meat; during the transportation from the farm to the slaughterhouse, broilers are exposed to a variety of potential stressors, including thermal imbalances, vibrations, withdrawal of water, social disruption and noise (Mitchell and Kettlewell, 1998). A number of studies have focused on the effects of transport stress on physiological blood parameters (Yalçın et al., 2004; Nijdam et al., 2005). Zhang et al. (2009) reported that transportation caused an increase in glycogenolysis and a decrease in glycogen in both breast and thigh muscles in broilers. Transport stress was in addition associated to enhanced skeletal muscle energy metabolism, to mitochondrial superoxide production, acceleration of lipid peroxidation, and to induction of cellular damage (Zhang et al., 2010). Presently, however, data on effects of pre-slaughter transportation on fatty acid profile of breast meat of broilers slaughtered at differing body weights are lacking. The aim of this study was to investigate the influence of pre-slaughter transport duration, as a stress factor, on meat nutrient and fatty acid composition of broiler breast muscles.

\section{MATERIAL AND METHODS}

\section{Broilers}

The study was conducted at spring on Ross broiler stocks slaughtered at one of the commercial processing plants in Turkey. Broilers were reared under commercial conditions until they reached to average 1.8 (lighter) or $2.6 \mathrm{~kg}$ (heavier), 36 and 46 days old, respectively. Broilers were fed by standard broiler rearing, growing and finisher diets. Feed was deprived $8 \mathrm{~h}$ before transport to slaughter. Transport duration was $1.5 \mathrm{~h}$ (short) or $3 \mathrm{~h}$ (long). Broilers were allowed to rest $1 \mathrm{~h}$ before being slaughtered.

All broilers were slaughtered in identical conditions; electrically stunned, bled, scalded, defeathered, eviscerated and pre-chilled before deboning. A total of 48 carcasses were randomly sampled, with an equal number of samples for each class (light weight and short transport, heavy weight and short transport, 
light weight and long transport, heavy weight and long transport). Breast muscle was separated from the carcass and placed in plastic bags, coded and transported in ice to laboratory. Samples were stored in freezer at $-20^{\circ} \mathrm{C}$. The following day lyophilization was performed prior to nutrient content and fatty acids analysis.

\section{Analytical measurements}

Half of the samples were used for protein (Kjeldahl method), lipid and ash content determination according to AOAC (1990) methods. For the determination of total fatty acids composition, lipids were extracted according to the method of Folch et al. (1957). Briefly, $5 \mathrm{~g}$ homogenized meat sample was blended twice with extraction solvent chloroform/methanol $(1: 2, \mathrm{v} / \mathrm{v})$, filtered, placed in separator funnels, and mixed with saline solution $(0.88 \% \mathrm{KCl})$. After separation in two phases, the methanol aqueous fraction was discarded, and the lipid chloroform fraction washed with distilled water/methanol $(1: 1, \mathrm{v} / \mathrm{v})$. Following a further filtration and evaporation by means of a rotary evaporator, lipid extracts were prepared for transesterification in n-heptane according to Christie (1982) and transferred to test tubes for subsequent gas chromatographic analysis, performed on a Thermo Quest (model 8000 Series Top, Milan, Italy) instrument equipped with a Omegawax 250 capillary column (length $30 \mathrm{~m}$, internal diameter $0.25 \mathrm{~mm}$, Supelco, Bellafonte, PA, USA). The percentage of total saturated fatty acids (SFA), monounsaturated fatty acids (MUFA), total unsaturated fatty acids (UFA), polyunsaturated fatty acids (PUFA), $\omega 3$ and $\omega 6$ were calculated from individual fatty acid percentages.

\section{Statistical analysis}

Data were subjected to ANOVA by the GLM procedure with a model including the combined effect of age and slaughter weight (ASw), transport duration (Td) and interaction between them using SAS $^{\circledR}$ software (2008). When significant differences occurred for a response $(\mathrm{P}<0.05)$, Tukey was performed to separate treatment means.

\section{RESULTS AND DISCUSSION}

Effects of slaughter weight and transport duration on meat nutrient composition are given in Table 1. No significant differences were found among the ASw groups regarding moisture, ash, protein and lipid content, while transport duration affected moisture, protein and lipid content. When considering ash, protein and 
Table 1. Effect of slaughter weight and transport duration on meat nutrient composition

\begin{tabular}{|c|c|c|c|c|c|c|c|}
\hline \multirow{2}{*}{$\begin{array}{l}\text { Nutritrients } \\
\%\end{array}$} & \multicolumn{3}{|c|}{$\mathrm{ASw}$} & \multicolumn{3}{|c|}{$\mathrm{Td}$} & $\mathrm{ASw} \times \mathrm{Td}$ \\
\hline & light & heavy & $\mathrm{P}$ & short & long & $\mathrm{P}$ & $\mathrm{P}$ \\
\hline Moisture & 74.21 & 73.98 & N.S & 74.45 & 73.74 & $<0.001$ & N.S \\
\hline Ash & 1.15 & 1.14 & N.S & 1.13 & 1.15 & N.S & N.S \\
\hline Protein & 23.27 & 23.34 & N.S & 23.15 & 23.46 & 0.017 & 0.005 \\
\hline Lipid & 0.72 & 0.83 & N.S & 0.62 & 0.92 & 0.027 & N.S \\
\hline
\end{tabular}

NS - not significant; ASw - combined effect of age and slaughter weight; Td - transport duration

lipid content calculated on dry matter, no differences were detected among the two groups (data not shown). Lower moisture but higher lipid content was found in the broilers transported for longer duration.

Interaction $\mathrm{ASw} \times \mathrm{Td}$ indicated that heavier broilers transported for longer duration had the higher protein content $(23.7 \%)$ than those transported for shorter duration $(23.0 \%)$, while lighter broilers had similar protein content regardless of body weight (data not shown in the Table).

Least square means of the fatty acids analysed are presented in Table 2 . The main component of SFA was palmitic (16:0), while oleic (18:1cis n-9) acid was the main MUFA. Linoleic acid (C18:2cis n-6) formed as a major component of PUFA in the breast meat. The 20-carbon family (long chain) of n-3 PUFA was mainly docosapentaenoic (DPA, C22:5 n-3) and docosahexaenoic (DHA, C22:6 n-3) fatty acids. Fatty acid composition was significantly influenced by the combined effect of age and slaughter weight (ASw). Heavier broilers produced breast meat with a lower content of pentadecanoic (C15:0), margaric (C17:0) and C16:0 n-9 fatty acids. However, a significantly higher content of palmitic (C16:0) acid resulted a higher content of SFA in heavier broilers breast meat. Although lighter broilers had lower palmitoleic (C16:1 n-7) acid content, total MUFA was similar between body weight groups. The lower content of PUFA obtained for heavier broilers was mainly due to lower content of $\alpha$-linoliec (C18:3 n-3), 4,7,10,13,16-docosapentaenoic (C22:5 n-6) and decosahexaenoic (C22:6 n-3) acids. Thus, ratios of PUFA/SFA was lower in heavier broilers. Total $\mathrm{n}-3$ was significantly higher in the meat from lighter broilers than those from heavier.

There was no effect of transport duration on total SFA. The decrease in MUFA by longer transportation was due to a decrease in the C16:1 n-9 content. While there were significant decreases in dihomogammalinoleic (C20:3cis n-6) and 4,7,10,13,16-docosapentaenoic (C22:5 n-6) content by longer transportation, $\alpha$-linoleic acid (C18:3 n-3) increased. These differences, although significant, were not large in magnitude to result in significant difference in the total PUFA. Transport duration had no effect on PUFA/ SFA. A higher $n-3 / n-6$ ratio in the meat from broilers transported for longer duration was obtained compared to those transported for shorter duration. 
Table 2. Least square means of raw breast (without skin) fatty acid composition

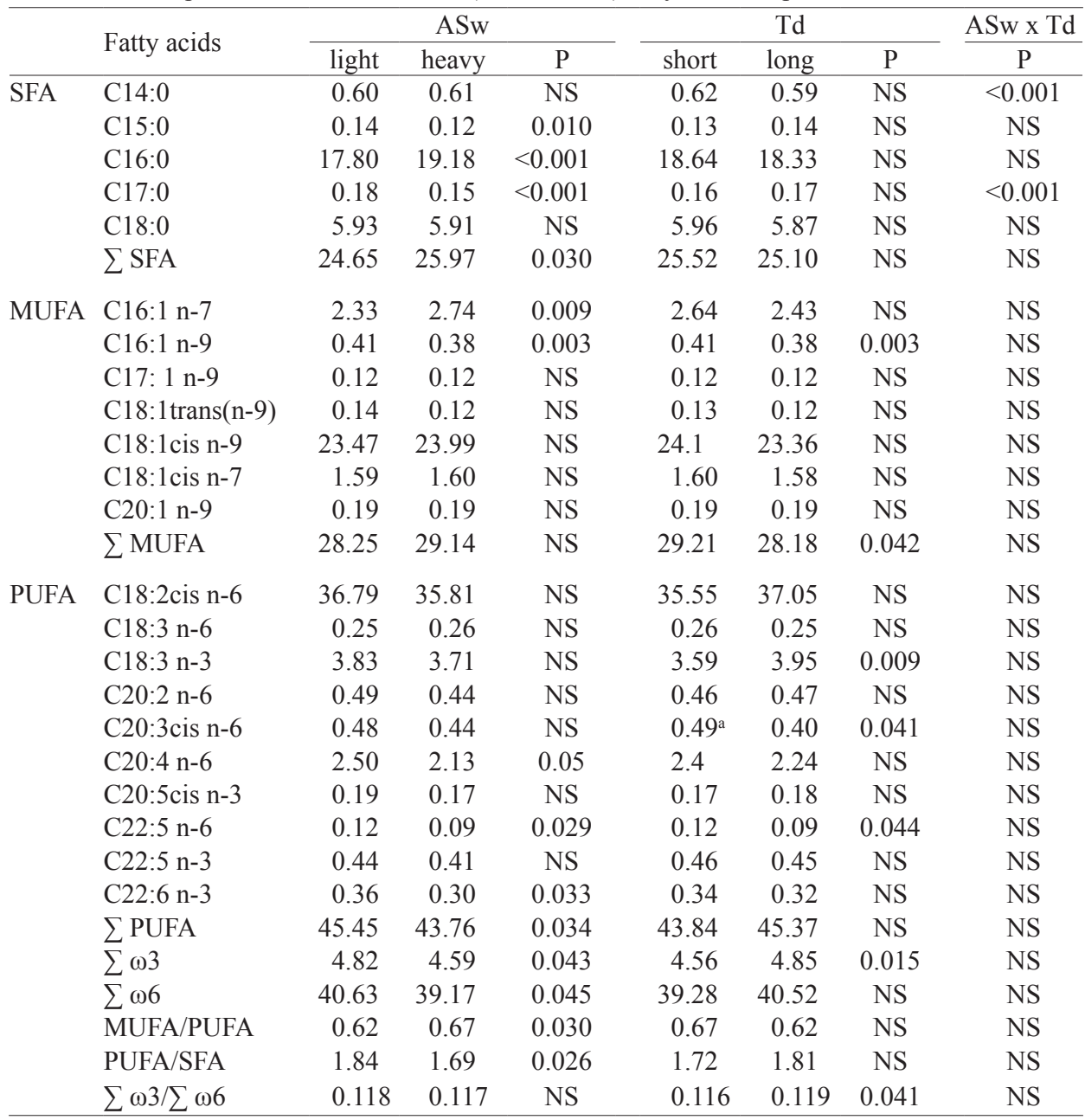

NS - not significant; ASw - combined effect of Age and Slaughter weight; Td - transport duration. SFA - saturated fatty acids, MUFA - monounsaturated fatty acids, PUFA - polyunsaturated fatty acids

Interaction ASw x Td was significant only for myristic and margaric acids. However, $2.6 \mathrm{~kg}$ broilers transported for $3 \mathrm{~h}$ had significantly higher myristic and lower margaric contents, compared with $1.8 \mathrm{~kg}$ broilers transported for $1.5 \mathrm{~h}$.

The results support the hypothesis that nutrient composition of the broiler breast meat is not influenced by body weight. This is in agreement with findings reported in literature (Berri et al., 2001) showing that experimentally selected broilers for body weight had similar protein and dry matter contents of breast meat to birds that were not subjected to this selection. 
On the other hand, the composition of breast muscle changed due to transport duration. The higher lipid obtained by longer transportation was mainly due to lower moisture content. The longer transport may have caused dehydration of the birds, being no able to restore from water lost due to the normal physiological activity. Previous studies suggested that longer transportation results in higher plasma corticosterone concentration (Zhang et al., 2009; Vošmerová et al., 2010). King (1997) reported that stress created by adrenocorticotropic hormone treatment increased lipid and decreased moisture content. A positive correlation between carcass fatness and cortisol was also reported in pigs (Foury et al., 2005).

Fatty acid composition of the meat affects meat quality, in particular shelf life and flavour (Wood et al., 2004). The increase in total SFA detected for heavy broilers could be related to their fatness, as previously reported from other authors (DeSmet et al., 2004). However, total lipid content in the breast meat of heavy broilers was slightly, but not significantly, different from lighter broilers, so this statement cannot be confirmed here. The level of PUFA in poultry meat can play an important role in the susceptibility of poultry meat to lipid oxidation which leads to discoloration, increase in drip loss during storage, decrease in shelf-life and off flavour development. Rymer and Givens (2005) reported that higher concentration of n-3 PUFA, particularly $\alpha$-linoleic acid, is associated with oxidative instability.

The higher levels of $\alpha$-linoleic acid obtained from broilers transported for the longer duration may indicate that $3 \mathrm{~h}$ of transportation could increase lipid oxidation in breast meat. Thus, protection against oxidation may be necessary by increments in the transport duration. It was also reported that n-3 PUFA accumulation and higher levels of arachidonic acid (C20:4 n-6) is related to PSE syndrome occurrence (Soares et al., 2003; Betti et al., 2009). Because lighter broilers had significantly higher arachidonic acid (C20:4 n-6), n-3 fatty acids and total PUFA content, we may conclude that slaughter weight and age may contribute to the occurrence of PSE syndrome.

\section{CONCLUSIONS}

The obtained results indicate that transport duration affects only moderately the fatty acid composition of poultry meat; in particular heavier weights and a longer transport duration have unfavourable effect of fatty acid composition, by increasing total saturated and monounsaturated and by decreasing polyunsaturated fatty acids. The reduction of the impact of stress related to transport duration is now, and it will be even more in the future, a strategic issue, as the number of authorized poultry slaughterhouses is decreasing all over in Europe. 


\section{ACKNOWLEDGEMENTS}

The authors express their appreciation to Mahmut Yazgan for his excellent technical assistance at the slaughterhouse.

\section{REFERENCES}

AOAC, 1990. Association of Analytical Chemists, Official Methods of Analysis. $15^{\text {th }}$ Editrion. Arlington, VA

Berri C., Wacrenier N., Millet N., Le Bihan-Duval E., 2001. Effect of selection for improved body composition on muscle and meat characteristics of broilers from experimental and commercial lines. Poultry Sci. 80, 833-838

Betti M., Schneider B.L., Wismer W.V., Carney V.L., Zuidhof M.J., Renema R.A., 2009. Omega-3enriched broiler meat: 2 . Functional properties, oxidative stability, and consumer acceptance. Poultry Sci. 88, 1085-1095

Christie W.W., 1982. The preparation of derivatives of lipids. In: W.W. Christie (Editor). Lipid Analysis. $2^{\text {nd }}$ Edition. Pergamon Press, New York, NY

Department of Health, 1994. Nutritional aspects of cardiovascular disease. Report on Health and Social Subjects No. 46. Her Majesty's Stationery Office, London (UK)

DeSemet S., Raes K., Demeyer D., 2004. Meat fatty acid composition as affected by fatness and genetic factors: A review. Anim. Res. 53, 81-98

Folch J., Lees M., Sloane-Stanley H., 1957. A simple method for the isolation and purification of total lipids from animal tissue. J. Biol. Chem. 226, 497-509

Foury A., Devillers N., Sanchez M.P., Griffon H., Le Roy P., Mormède P., 2005. Stress hormones, carcass composition and meat quality in Large White $\times$ Duroc pigs. Meat Sci. 69, 703-707

King Y.T., 1997. The physical and chemical characteristics of broiler meat and liver as affected by adrenocorticosterone hormone and acute heat stress. Diss. Abstracts Int. B57, 169

Mitchell M.A., Kettlewell P.J., 1998. Physiological stress and welfare of broiler chickens in transit: solutions not problems! Poultry Sci. 77, 1803-1814

Nijdam E., Delezie E., Lambooij E., Nabuurs M.J., Decuypere E., Stegeman J.A., 2005. Feed withdrawal of broilers before transport changes plasma hormone and metabolite concentrations. Poultry Sci. 84, 1146-1152

Rymer C., Givens D.I., 2005. n-3 fatty acid enrichment of edible tissue of poultry: A review. Lipids $40,121-130$

SAS/STAT ${ }^{\circledR}, 2008$. 9.2 User's Guide, SAS Institute Inc. Cary, NC

Soares A.L., Ida E.L., Miyomoto S., Blazques F.J.H., Olivo R., Pinherio J.W., Shimokamaki M., 2003. Phospholipase A2 activity in poultry PSE, pale soft, exudative. J. Food Biochem. 27, 309-319

Szymczyk B., Pisulewski P.M., Szczurek W., Hanczakowski P., 2001. Effects of conjugated linoleic acid on growth performance, feed conversion efficiency, and subsequent carcass quality in broiler chickens. Brit. J. Nutr. 85, 465-473

Vošmerová P., Bedáňová I., Chloupek P., Chloupek J., Suchý P., Večerek Jr.V., 2010. Transportinduced changes in selected biochemical indices in broilers as affected by ambient temperatures. Acta Vet. Brno 79, S41-S46

Wood J.D., Richardson R.I., Nute G.R., Fisher A.V., Campo M.M., Kasapidou E., Sheard P.R., Enser M., 2004. Effects of fatty acids on meat quality: a review. Meat Sci. 66, 21-32 
Yalcin S., Ozkan S., Oktay G., Cabuk M., Erbayraktar Z., Bilgili S.F., 2004. Age-related effects of catching, crating, and transportation at different seasons on core body temperature and physiological blood parameters in broilers. J. Appl. Poultry Res. 13, 549-560

Zanetti E., De Marchi M., Dalvit C., Molette C., Remignon H., Cassandro M., 2010. Carcass characteristics and qualitative meat traits of three Italian local chicken breeds. Brit. Poultry Sci. 51, 629-634

Zhang L., Yue H.Y., Wu S.G., Xu L., Zhang H.J., Yan H.J., Cao Y.L., Gong Y.S., Qi G.H., 2010. Transport stress in broilers. II. Superoxide production, adenosine phosphate concentrations, and mRNA levels of avian uncoupling protein, avian adenine nucleotide translocator, and avian peroxisome proliferator-activated receptor- $\gamma$ coactivator- $1 \alpha$ in skeletal muscles. Poultry Sci. 89, 393-400

Zhang L., Yue H.Y., Zhang H.J., Xu L., Wu S.G., Yan H.J., Gong Y.S., Qi G.H., 2009. Transport stress in broilers: I. Blood metabolism, glycolytic potential, and meat quality. Poultry Sci. 88, 2033-2041 